\title{
Direito à cidade, participação social e a política urbana no contexto brasileiro
}

\author{
Right to the city, social participation and urban policy in the brazilian context
}

\author{
Andréa Luiza Curralinho Braga ${ }^{1}$ \\ Huáscar Fialho Pessali ${ }^{2}$
}

\begin{abstract}
Resumo
O artigo apresenta a análise sobre a política de desenvolvimento urbano no contexto sóciohistórico brasileiro e suas mudanças pautadas à luz da concepção do direito à cidade e do movimento denominado Reforma Urbana. Aborda as alterações no âmbito jurídicoadministrativo impulsionado por diversos atores sociais após a Constituição de 1988 e na institucionalidade dos processos democráticos participativos. Tal análise apresenta em suas conclusões os desafios da construção da política urbana e participação entre os atores sociais, e a disputa por interesses diversos na arquitetura participativa.
\end{abstract}

Palavras-chave: Política urbana; Gestão democrática; Desenvolvimento urbano.

\begin{abstract}
This subject discusses on urban planning, it was possible to retrace the conjuncture politics in brazilian, detaching aspects of this process until the approval of right to the city and movement for the Urban Reformation. Also the incorporation of new references urban playing instruments in recognized beddings, in view of that, this movement appeared during the retaken of the democracy in the country and constituted as basic element of the Urban Politics in the Constituent of 1988 in experience and operation of democratic participation. This paper presents in its conclusions the challenges of building the participation of social actors, the competition for different interests and different political projects in participative architecture.

Keywords: Urban policy; Participative democracy; Urban development.
\end{abstract}

\footnotetext{
${ }^{1}$ Doutoranda em Políticas Públicas pela Universidade Federal do Paraná. E-mail: andrea.braga@ufpr.br.

${ }^{2}$ Doutor em Economia (New School For Social Research). Professor dos Programas de Pós-graduação em Políticas Públicas e Ciência Política da UFPR.
} 


\section{Introdução}

O último dado censitário do Instituto Brasileiro de Geografia e Estatística (IBGE, 2010) mostra que atualmente $85 \%$ da população brasileira vive nas cidades, sendo registrado que até o final da década de 1930 esse percentual não passava de 15\%. Na constituição das cidades brasileiras, os problemas do crescimento acelerado e a construção social desigual do espaço propagaram-se e materializaram-se em diversas expressões, seja pela precariedade habitacional, segregação socioespacial, degradação ambiental, problemas de infraestrutura, que passaram a retratar e reproduzir um quadro de injustiças e desigualdades sociais na questão urbana.

As características da trajetória histórica da urbanização brasileira no século XXI apontam para um crescimento, adensamento e expansão contígua da malha urbana, com padrões predominantemente desiguais de acesso a terra. Assim, nas últimas três décadas há, pelo quadro apresentado na realidade da produção das cidades, um processo de enfrentamento e mobilização que aposta em incidir no quadro de exclusão construído no decorrer da história brasileira, via movimento denominado Reforma Urbana.

Este artigo pretende, num primeiro momento, realizar reflexão sobre o debate acerca da Reforma Urbana e do Direito à Cidade e de como os preceitos que envolvem o "direito a ter direitos" incorporam-se como agenda política de diversos atores e coletivos sociais para o enfrentamento da questão urbana no Brasil.

$\mathrm{O}$ artigo retrata o histórico do planejamento urbano no país e como nas últimas três décadas a dimensão normativa e institucional relacionada ao Direito à Cidade e as pautas coletivas de participação popular, função social da cidade e propriedade e direitos de cidadania incorpora-se nas leis e na formulação das políticas de desenvolvimento urbano brasileiras.

Ainda, o artigo busca problematizar que, mesmo com os avanços legais e a institucionalidade de mecanismos de estruturação da política urbana no Brasil fundamentada por pautas populares, os processos de luta política não se dão de forma consensuada, mas se expressam em permanente disputa de projetos políticos e concepções de acesso à cidade e à terra urbana de forma distinta. Desse modo, tais disputas se dão entre as pautas populares e políticas includentes e redistributivas e as demandas de elites poderosas, incluindo 
proprietários de "latifúndios urbanos", setores empresariais e oligarquias familiares nas relações de poder que abrangem a produção e apropriação da cidade.

\section{Direito à cidade e o Movimento da Reforma Urbana no Brasil}

O conceito de Direito à Cidade foi desenvolvido pelo sociólogo francês Henri Lefebvre em seu livro de 1968 denominado Le droit à la ville. Ele define o direito à cidade como um direito de não exclusão da sociedade das qualidades e benefícios da vida urbana, compreendendo a polis como um local de produção coletiva em que todos deveriam ter acesso aos seus bens e intervir nas decisões sobre a produção do espaço em que habitam, ou seja, o debate do direito à cidade reflete-se no "direito à vida urbana, transformada, renovada" (LEFEBVRE, 1991, p. 117). Ainda sobre a concepção do Direito à Cidade, o geógrafo David Harvey complementa tal conceito com a seguinte análise:

O direito à cidade é muito mais do que a liberdade individual para acessar os recursos urbanos: é o direito de mudar a nós mesmos, mudando a cidade. Aliás, com frequência, não se trata de um direito individual uma vez que esta transformação depende, inevitavelmente, do exercício de um poder coletivo para remodelar os processos de urbanização. A liberdade de criar e recriar nossas cidades e a nós mesmos é, eu quero argumentar, um dos mais preciosos e dos mais negligenciados dos nossos direitos. (HARVEY, 2013, p. 28).

Essas concepções trazidas por teóricos sociais delineiam-se não somente como reflexões no âmbito normativo, mas como agenda política e bandeira de luta de diversos atores e movimentos sociais em uma articulação que se inicia na década de 1960 no Brasil, denominado Movimento da Reforma Urbana.

Afirma-se que esse movimento tem como marco histórico o Seminário Nacional de Habitação e Reforma Urbana, que ocorreu em 1963. O Seminário apostou em refletir sobre parâmetros para demarcar o crescimento das cidades que começava a se delinear. Nesse evento produziu-se um documento que predizia um conjunto de medidas estatais, visando ao justo uso do solo urbano, à ordenação das aglomerações urbanas e ao fornecimento de habitação digna para a população. A definição do documento previa como Reforma Urbana: 
Um conjunto de medidas estatais, que coloca a Reforma Urbana como atribuição do governo federal; solo urbano, ou terra urbana, que estava no cerne ou na origem do problema, deveria ter seu uso de forma justa, numa alusão à especulação imobiliária que deveria ser combatida; ordenação e equipamento das aglomerações pressupunham um planejamento físico das cidades; e por fim, fornecimento de habitações a todas as famílias, que foi o problema inicial que gerou os debates que agregaram questões mais complexas, e que deveria ser direito de todos (RIBEIRO; PONTUAL, 2009, p. 35).

A articulação inicial dessa frente foi desmobilizada diante do golpe da Ditadura Militar de 1964. Tal golpe interrompeu as reclamações das organizações populares em torno da Reforma Urbana, suprimindo as ações participativas e reivindicatórias de diversas redes por um planejamento urbano centralizador e tecnocrático.

Desse modo, a retomada das reivindicações coletivas no que se denomina como Reforma Urbana foi reiniciada na metade dos anos de 1970 e promoveu, com outras frentes, o movimento de democratização do país, sendo levantadas bandeiras de luta na construção do direito a ter direitos, no acesso aos bens produzidos coletivamente nas cidades e na participação popular.

O movimento articulado, denominado Reforma Urbana, definia diversas pautas formadas por esses coletivos sociais, produzindo uma interface com as demandas, pleitos e desejos dos diferentes grupos na cidade e incidência de ações diretas de embate, disputa e negociação com o Estado.

Santos (2002) e Santos Junior (2001) constatam que o movimento pela Reforma Urbana brasileira desde os anos 1980 vem arquitetando um diagnóstico em torno da produção e gestão das cidades e esse movimento propõe uma agenda centrada: (i) na institucionalização da gestão democrática das cidades; (ii) na municipalização da política urbana; (iii) na regulação pública do solo urbano com base no princípio da função social da propriedade imobiliária; (iv) na inversão de prioridade no tocante à política de investimentos urbanos.

A partir de 1987, há um processo de reconfiguração do movimento pela Reforma Urbana, que resultou na formação do Fórum Nacional da Reforma Urbana (FNRU). O FNRU é uma rede articulada de diversos coletivos sociais, composta por entidades de todas as regiões do país e coordenada por um conjunto de organizações: FASE - Federação de Órgãos para Assistência Social e Educacional; MNLM - Movimento Nacional de Luta por Moradia; 
UNMP - União Nacional por Moradia Popular; CMP - Central de Movimentos Populares; CONAM - Confederação Nacional de Associações de Moradores; CFESS - Conselho Federal de Serviço Social; FENAE - Federação Nacional das Associações de Empregados da Caixa Econômica; FISENGE - Federação Interestadual dos Sindicatos de Engenheiros, FNA - Federação Nacional de Arquitetos; Instituto Polis - Instituto de Estudos, Formação e Assessoria em Políticas Sociais; IBAM - Instituto Brasileiro de Administração Municipal; IBASE - Instituto Brasileiro de Análises Sociais e Econômicas; ANTP - Associação Nacional de Transportes Públicos; COHRE Américas - Centro pelo Direito à Moradia contra Despejos; AGB - Associação dos Geógrafos Brasileiros; FENEA - Federação Nacional dos Estudantes de Arquitetura e Urbanismo do Brasil; CAAP - Centro de Assessoria à Autogestão Popular; ABEA - Associação Brasileira de Ensino de Arquitetura e Urbanismo; Fundação Bento Rubião - Centro de Defesa dos Direitos Humanos; Observatório das Metrópoles IPPUR/UFRJ/FASE; Habitat para Humanidade Brasil; e ActionAid Brasil.

O FNRU vem atuando em várias frentes: desde interações diretas com o Estado; na inserção de atores que compõem o FNRU em instituições participativas, como conselhos e conferências; na organização de cursos de capacitação; na discussão e elaboração de planos diretores; em propostas de projetos de leis que incidiram na Constituição de 1988 e no Estatuto da Cidade; na defesa da institucionalização de um Sistema Nacional de Desenvolvimento Urbano, entre outras.

Em exame sobre a incidência do FNRU no desenho e na implementação das políticas urbanas nacionais, Orlando dos Santos Junior (2009) realiza análise em que busca responder: em que medida as propostas presentes na agenda do FNRU foram incorporadas pelo governo? Apesar de sua análise indicar êxito em algumas ações de estratégia coletiva, ressaltam-se as diversas incertezas na construção e na sustentação de uma agenda alternativa para o enfrentamento das desigualdades sociais nas cidades e, ainda, a disputa de conflitos de interesses.

Entre os principais impactos, aponta os indícios da continuidade de fragmentação das políticas urbanas, em que se avaliam as falhas no que deveria se constituir uma política nacional de desenvolvimento urbano (MARICATO; SANTOS JUNIOR, 2007).

A nosso ver, é a combinação particular desses elementos, em suas relações com a herança pesada da lógica de gestão do território excludente e predatória, que tem ditado as marchas e contramarchas da agenda da Reforma Urbana no país. Se, por um lado, ela não 
logrou constituir uma base de sustentação política para incidir profunda e amplamente na dinâmica estatal, assim como relações entre sociedade política e sociedade civil de forma a promover a gestão das cidades na direção de um espaço mais coeso, includente e sustentável, por outro, tem sido uma fonte permanente de tensionamento e inovação cultural introduzida pelos atores sociais, que ampliou do ponto de vista territorial e político o espaço da democracia brasileira (ROLNIK, 2009, p. 37).

Diante de tais inflexões, considera-se relevante pontuar o movimento organizativo do FNRU, em que se retoma aqui a concepção de Dagnino (2004) referente à noção de projetos políticos. A autora cita que há uma unidade entre ação e representação, assim, à noção de projetos políticos não se reduzem somente estratégias de atuação em sentido conciso, mas expressam, veiculam e produzem significados que integram nuances culturais mais amplas. "Um projeto por um lado implica num horizonte mais ou menos aberto de possibilidades, estruturado em narrativas existentes, mas também em orientação, missão, num engajamento autoconsciente de um futuro transformável” (MISCHE, 2001 apud DAGNINO, 2004, p. 40).

Nesse sentido, no contexto de organização do FNRU há um ideário consensuado (FARIA, 2012) que busca sustentar o projeto da Reforma Urbana a partir de concordâncias e são investidos empenhos expressivos para conduzir os debates internos, no pacto entre as visões distintas e a interação entre os diversos sujeitos. Assim, é necessário compreender como são arquitetados os repertórios de ação coletiva, a forma de geração dos processos de coesão, construção de identidades e as interpretações que fazem os atores criarem as aceitações nas diferenças, pois os consensos formados nos movimentos sociais também são aprofundados de disputas.

No texto de Gusso (2013), denominado Pelas ruas e gabinetes: amplificando os frames $^{3}$ da Reforma Urbana no Brasil, o autor procura trazer a reflexão sobre como é definida a agenda da Reforma Urbana e a experiência e contrapontos entre diversos atores sociais em

\footnotetext{
${ }^{3}$ O conceito básico de frame indicado por Erving Goffman (2012) corresponde a quadros interpretativos. Assim, articulam-se estratégias e ações com base no enquadramento coletivo da realidade, delineando um fator com potencial de explicar o nascimento e o desenvolvimento de identidades políticas. Para isso, unem-se esforços conscientes e estratégicos desenvolvidos por grupos para formar um entendimento compartilhado do mundo e de si, que motiva e legitima as ações coletivas. Para a formação dos quadros são identificadas três fases distintas: (i) diagnóstico - identificação de problemas e atribuição de causas e responsáveis; (ii) prognóstico - réplicas ou alternativas de recursos necessárias para reverter uma situação; e (iii) mobilização - construção de motivos para engajamento e ação.
} 
torno de diagnósticos e que caminhos devem ser seguidos para a mudança da questão urbana no Brasil.

Em relação à atualização do ideário da Reforma Urbana, é perceptível que os quadros mobilizatórios continuam em disputa, sendo mediados por análises pessimistas e otimistas, mas que refletem diferentes entendimentos sobre a forma de realizar o projeto político da Reforma Urbana. Se, por um lado, o diagnóstico é "ponto pacífico", os quadros de prognóstico e os quadros de mobilização refletem a própria diversidade de atores que compõem o FNRU, sendo o grau de consenso, portanto, variável (GUSSO, 2013, p. 25).

Dessa forma, argumenta-se a contradição entre o predomínio do discurso do direito à cidade e a permanência da cidade como negação do direito, fundada não apenas no confronto com ideologias, mas nas desigualdades constituídas historicamente de produção de espaços e nos próprios limites e justificação de valores e autoridades do planejamento urbano politizado (FARIA, 2012).

Desse modo, mostra-se relevante compreender a trajetória histórica do processo de planejamento urbano no Brasil e como se estrutura a política urbana na atualidade, pautada nos princípios que regem o Direito à Cidade e a agenda política da Reforma Urbana no Brasil, mas que ao analisar os processos de melhorias no que se refere de fato à reversão do contexto excludente e desigual na produção das cidades brasileiras, identifica-se que escassos foram os avanços.

\section{Planejamento e política urbana no contexto brasileiro: produção do espaço e suas contradições}

Para Lefebvre (1991), o conceito de cidade formula-se como "[...] um objeto espacial que ocupa um lugar e uma situação, a construção das cidades está relacionada à materialidade resultante das práticas sociais: é a realidade presente, imediata, dado prático-sensível, arquitetônico" (LEFEBVRE, 1991, p. 65). O autor ainda identifica a cidade como espaço físico no qual as pessoas vivem, circulam, trabalham, moram, arquitetando e transformando o ambiente de acordo com suas necessidades e interesses.

Tais conceitos indicam a cidade como o resultado de um complexo e contínuo processo de produção do espaço, que envolve diferentes forças e projetos societários distintos 
e uma diversidade de agentes da sociedade civil e agentes estatais, os quais moldam as políticas públicas urbanas.

Desse modo, as políticas urbanas representam, portanto, uma concepção de projeto de cidade. A política urbana abrange "[...] o produto de contradições urbanas, de relações entre diversas forças sociais quanto ao modo de ocupação, ou de produção do espaço urbano" (LOJKINE, 1997, p. 57).

Também se ressalta que a política urbana é uma política pública e de tal modo segue a estrutura de intervenção do poder público em relação às intersecções sobre as cidades, no ciclo que abrange: (i) formação de agenda; (ii) plano de governo; (iii) processo de tomada de decisões; (iv) implementação e (v) avaliação da política. É destacado aqui o conceito de Dye (1984) sobre a política pública baseada no que “[...] o governo escolhe fazer, ou não fazer" (DYE, 1984, p. 2).

Referente à formulação do planejamento urbano no Brasil, a escolha do que fazer ou não fazer na formulação da política e planejamento da cidade está relacionada a disputas de projetos, intencionalidades, ideologias, interesses diversos que interferem diretamente na formação e no desenvolvimento das cidades.

A urbanização no Brasil é um fenômeno que envolve diretamente o planejamento urbano nas ações que preveem a implementação de infraestrutura e equipamentos públicos. Segundo Hobsbawn (1997), o crescimento das cidades diminuiu drasticamente a população rural. Tendo como aspectos que influenciaram esse fato no início do século $\mathrm{XX}$, além da industrialização no país, estão a estruturação fundiária urbana, a ampliação do proletariado, a expansão urbana que gerou a aglomeração populacional acelerada e a necessidade de ampliação de equipamentos públicos e de planejamento, a fim de adequar as cidades às novas relações da produção e do poder no país.

Ainda há a visão de Déak (1999) sobre o processo de urbanização no Brasil, em que observa:

[...] foi a partir do segundo quartel do século XX que a escala alcançada pela urbanização começou a provocar iniciativas por parte do Estado e modificações na administração pública. Um dos resultados nesse sentido é o aparecimento de uma nova atividade governamental com a finalidade específica de tratar dessas novas entidades que estavam surgindo: as aglomerações urbanas. É o planejamento e, particularmente, do planejamento urbano, cujos primórdios podem ser situados no Estado Novo - no advento do qual Otávio Ianni via, significativamente, a consolidação de "uma vitória importante" [...] da cidade sobre o campo (DEÁK, 1999, p. 12). 
Do final do século XIX datam os primeiros registros de cortiços e ocupação dos morros cariocas com as moradias populares. Mesmo que as cidades ainda não fossem regidas pela dinâmica do capitalismo industrial avançado, já tinham como marca a diferenciação socioespacial, pela qual a população mais pobre, via de regra, era impelida para as áreas menos privilegiadas e sem infraestrutura. Desse modo, Ferreira (2005) explicita que surgem as experiências de ações pautadas na higienização social, com o afastamento das classes populares para áreas que não seriam utilizadas e não eram de interesse das elites locais. Por essa razão, as primeiras grandes intervenções urbanas estatais visaram criar uma nova imagem da cidade, em consonância com os modelos estéticos europeus. Nesse processo, “[...] as elites buscavam afastar de suas vistas - e das vistas do estrangeiro - o populacho inculto, desprovido de maneiras civilizadas, mestiço. As medidas urbanas criaram uma cidade 'para inglês ver"” (RIBEIRO; SANTOS, 1981, apud FERREIRA, 2005, p. 5).

Essas evidências mostram que:

\begin{abstract}
Não foi só o governo. Mas a sociedade brasileira em peso embriagou-se, desde os tempos da abolição e da república velha, com as idealizações sobre progresso e a modernização. A salvação parecia estar nas cidades, onde o futuro já havia chegado. Então era só vir para elas e desfrutar de fantasias como emprego pleno, assistência social providenciada pelo Estado, lazer, novas oportunidades para os filhos... Não aconteceu nada disso, é claro, e, aos poucos, os sonhos viraram pesadelos (SANTOS, 1993, p. 2).
\end{abstract}

Para Villaça (1999), no artigo no qual fala sobre a contribuição para a história do planejamento urbano, este processo no Brasil pode ser dividido em três principais períodos: (i) o primeiro inicia-se no final do século XIX, por volta de 1875, e vai até o ano de 1930, em que o planejamento urbano é marcado pelos planos de embelezamento e melhoramentos da cidade, herdeiros da forma monumental que exaltava as elites e destruiria a forma de organização do espaço colonial; (ii) o segundo período segue de 1930 até por volta de 1992 e é marcado pelo planejamento como técnica de base científica, indispensável para resolver problemas urbanos, que muda o foco da cidade bela para a cidade eficiente; (iii) após 1992 inicia-se o terceiro período, que perdura até o fim do século $\mathrm{XX}$, sendo marcado por princípios da Reforma Urbana, como um instrumento de politização, mas também se desgasta, em virtude das possibilidades de manipulação e desviado por setores reacionários que dominam a produção do espaço. Tais setores, representados pelas elites econômicas, pauta-se 
em conformações de modelos de planejamento urbano de empresários, urbanistas e agentes financeiros e estatais fazem prevalecer seus interesses comuns sobre os projetos urbanísticos.

Ao visitar o pensamento de alguns autores que discutem o planejamento urbano na trajetória brasileira, como Ferreira (2005), Maricato (2000), Rolnik (1994) e Villaça (1999), percebe-se que há consenso entre eles de que o processo de urbanização no Brasil é marcado pela lógica da produção desigual do espaço e de que o acesso à terra legal e o direito à cidade de forma ampliada são privilégios de um grupo restrito. As matrizes que fundamentaram o planejamento e a legislação urbana no Brasil, que preveem a função social da terra e o acesso às cidades como direito de todos, expressam o hiato do que de fato é constatado na permanência da exclusão urbanística de uma parcela significativa da população. Nesse ponto, Maricato (2000) discorre sobre as incongruências entre o que se prevê no ideário do planejamento urbano e das leis urbanísticas e o que se materializa nas relações da produção dos espaços. Segundo suas palavras, "em ideias fora do lugar e o lugar fora das ideias" (MARICATO, 2000).

A autora ainda reafirma tal pensamento pautado na análise da concepção liberal da igualdade de todos e no princípio do modernismo, mas defende que o lugar fica fora das ideias no momento em que os planos e leis no Brasil aplicam-se a uma parcela da sociedade, reafirmando e reproduzindo desigualdades e privilégios. "Para a cidade ilegal não há planos, nem ordem. Aliás, ela não é conhecida em suas dimensões e características. Trata-se de um lugar fora das ideias" (MARICATO, 2000, p. 122). Essa lógica determina o modelo de crescimento urbano do Brasil e o planejamento, pautado pela prioridade das obras viárias e incentivo fiscal, para o transporte individual; implantação periférica e precária de habitação popular; expansão horizontal urbana não planejada; destruição do ambiente natural; aumento de resíduos e poluição pelo consumo humano; manutenção de terrenos ociosos e sem cumprimento de sua função social, ou seja, resulta naquilo que é denominado lógica da desordem (KOWARICK, 1975).

Desse modo, ao examinar a urbanização e as ações de planejamento no Brasil, observa-se que esse processo não se deu de forma equânime, pois é evidente a distinção entre os bairros, tanto no que se refere ao perfil da população moradora, como nas diferenças urbanísticas, de infraestrutura, de conservação dos espaços e equipamentos públicos, enfim, o modelo de urbanização no Brasil é produzido em cima das desigualdades. 
Lojkine (1997) identifica três características principais sobre a urbanização e segregação espacial: (i) a oposição entre o centro e a periferia; (ii) a separação cada vez mais acentuada entre as áreas ocupadas pelas moradias das classes mais populares e aquelas ocupadas pelas classes mais privilegiadas; (iii) a separação entre as funções urbanas, que ficam contidas em zonas destinadas a funções específicas (comercial, industrial, residencial). Assim, é importante evidenciar que as relações e produções do planejamento urbano não se dão de forma neutra e isenta da influência e interesses de grupos distintos.

Sendo assim, o campo de acepções da política urbana ocorre primeiramente pelo território e pelas pessoas que lá vivem, no conjunto das reproduções sociais e, nesse contexto, o Estado é o intermediário e regulador dessas relações. Logo, as propostas e ações do Estado sobre o urbano podem ser implementadas por distintas formas e meios de apropriação e anseios no que se refere à produção do espaço.

No Brasil, citam-se diversas práticas que envolveram o planejamento e projetos urbanísticos das cidades brasileiras, desde o Estado Novo até o final da Ditadura Militar, na década de 1980, mas essas ações não se consolidaram de forma sistemática, estruturada, e os planos urbanísticos foram considerados ineficientes.

Desse modo, somente no contexto da Constituição de 1988 o planejamento urbano retomou sua importância normativa e política, adquirindo natureza jurídica e maior formalização no processo de elaboração e tentativa de articulação do planejamento e ações para as cidades. Nessa Constituição é que se incluem, pela primeira vez, dois artigos que tratam sobre a política urbana nos marcos normativos constitucionais brasileiros. Os Artigos 182 e 183 versam sobre a política de desenvolvimento urbano, que tem por finalidade ordenar o pleno avanço das funções sociais da cidade e garantir o bem-estar dos seus habitantes. $\mathrm{O}$ Artigo 182 tem como base a previsão do cumprimento e exercício da função social da propriedade, além de objetivar o uso social da terra urbana e incidir em uma distribuição mais equitativa do acesso a ela.

Já o Artigo 183, sobre o usucapião urbano, define a posse da área urbana para quem vive em terreno durante mais de cinco anos ininterruptamente, em que a área seja inferior a $250 \mathrm{~m}^{2}$ e o morador não disponha de outro imóvel. Esse artigo trata indiretamente da possibilidade de ampliar a validade das ocupações no Brasil. Além desse dispositivo, há também o dispositivo jurídico posterior que dispõe sobre concessão de uso especial para fins de moradia, de áreas públicas ocupadas com finalidade residencial. Instrumento 
complementar à medida de usucapião pautada na Medida Provisória $n^{0} 2220$, de 04 de setembro de 2001, e dispõe sobre a concessão de uso especial de que trata o $\S 1^{\circ}$ do Art. 183 da Constituição, cria o Conselho Nacional de Desenvolvimento Urbano - CNDU e dá outras providências. Logo, terra sem uso valida o direito de posse legítima, pois está cumprindo a função social da propriedade. Esse dispositivo também deveria ampliar a possibilidade dos processos de regularização fundiária das áreas urbanas e garantir os parâmetros urbanísticos, legais e sociais.

Os dispositivos que preveem os artigos 182 e 183 da Carta Magna definem uma nova fase para a questão das políticas de desenvolvimento urbano no Brasil. O Movimento da Reforma Urbana foi associado à conquista dessa inclusão, pois exibiu a proposta de emenda com mais de 130 mil assinaturas que previam a inserção, além desses, de diversos outros artigos vetados no capítulo sobre a política urbana na nova Constituição.

Ainda, para a regulamentação dos artigos constitucionais referentes à política urbana, após 11 anos de discussão e acordos políticos, foi instituída a Lei ${ }^{\circ} 10.257$, de julho de 2001, o Estatuto da Cidade. O Estatuto estabelece as diretrizes gerais da política urbana e a definição dos instrumentos urbanísticos, bem como prevê maior poder de controle do poder público sobre a organização urbana e obrigatoriedade da participação social no processo de planejamento das cidades.

Referentemente à gestão democrática das cidades, sobre os fundamentos da participação popular e controle social, o Estatuto da Cidade representou um grande avanço legal, pois destina um capítulo exclusivo sobre a gestão democrática. Em seu Artigo $2^{\circ}$, inciso II, prevê "[...] que a política urbana deve ser exercida com gestão democrática por meio da participação da população e de associações representativas dos vários segmentos da comunidade na formulação, execução e acompanhamento de planos, programas e projetos de desenvolvimento urbano" (BRASIL, 2001).

Esses artigos iniciais do Estatuto da Cidade trazem os princípios norteadores da aplicação dos diversos instrumentos constantes dessa lei. O Estatuto, em seu Capítulo IV, elenca as mais variadas formas de democracia, que permitem a participação popular, assegurando, no Artigo 43, a garantia da participação da população na gestão municipal, que está prevista por meio de debates, audiências, consultas públicas, iniciativa popular de projetos de lei e de planos, programas e projetos de desenvolvimento urbano e ainda pela composição de órgãos colegiados de política urbana e conferências sobre assuntos de 
interesse urbano, estas a serem desenvolvidas nas três esferas de governo (BRASIL, 2001). Ainda evidencia a possibilidade de emprego de qualquer outro desenho de participação que se revele necessário.

Versa-se, assim, sobre uma nova maneira de conjeturar o exercício do poder político, conjugando instituições representativas com os canais de participação direta. Principalmente, pela tendência de espaços institucionalizados que se proliferam após a Constituição de 1988, em que representantes escolhidos (ou eleitos) diretamente pela sociedade civil ou pelo poder público atuam na formulação, fiscalização e monitoramento de políticas públicas e sociais (GOHN, 2007). Como há exemplo no âmbito da política urbana dos Conselhos e Conferências das Cidades.

Após a promulgação do Estatuto da Cidade e o momento de efervescência dos processos de democratização da política urbana e gestão articulada do desenvolvimento das cidades, firma-se o compromisso do governo Lula em criar um ministério específico no campo do desenvolvimento urbano e em 2003, efetivada com a criação do Ministério das Cidades.

Com isso, ocorreu uma organização inovadora nas políticas urbanas brasileiras, que trazia como premissa a superação do recorte setorial da habitação para a concepção mais ampla da intersetorialidade urbana. Na análise de Koga (2003, p. 238), a intersetorialidade é entendida como um caminho e perspectiva ampliada para a política pública, a fim de articular estratégias, ações econômicas e macros de forma a incidir nos mesmos territórios conjuntamente.

O Ministério das Cidades ficou assim organizado pelos setores: (i) de habitação; (ii) de saneamento; (iii) de infraestrutura, planejamento urbano e ordenamento territorial; (iv) política nacional de transporte e mobilidade. Cada setor tem responsabilidade na elaboração e implementação de políticas e programas urbanos.

Para os atores ligados ao movimento social pela Reforma Urbana, a criação do Ministério das Cidades representava a possibilidade de avançar na democratização da gestão urbana, fazendo dela um dos pilares institucionais de sua agenda, ampliando os espaços de democracia participativa, até então experimentados sobretudo no âmbito local. A resposta a essa demanda, no interior do processo de organização do ministério, deu-se através da constituição de um Conselho Nacional das Cidades como parte integrante de sua estrutura e elemento central na formulação e negociação de políticas, e no qual tantos setores 
governamentais (dos três níveis de governo) como segmentos da sociedade civil (setor empresarial, sindicatos, organizações profissionais, ONGs, entidades acadêmicas e de pesquisa e movimentos populares) são representados, eleitos através de assembleias por segmentos, entre delegados presentes em Conferências Nacionais (ROLNIK, 2009, p. 35).

Desse modo, a estruturação da política urbana indicava o arranjo de ações governamentais que assumissem propostas e estratégias capazes de universalizar o acesso a bens urbanos, além de superar a cultura de fragmentação da gestão com ampla participação popular nos processos decisórios.

Após a criação do Ministério das Cidades, em 2003, ocorreu a I Conferência da Cidade e nessa conferência foi indicada a criação do Conselho das Cidades - Concidades. Essas instituições deram início à construção de uma estrutura normativa e representativa na política nacional de desenvolvimento urbano. O Ministério das Cidades, a Conferência das Cidades e o Concidades davam início à estrutura que previa o desenvolvimento da política urbana no Brasil.

Além das estruturas citadas, há a previsão da organização do Sistema Nacional de Desenvolvimento Urbano (SNDU). O indicativo da estruturação do SNDU foi deliberado em reunião da primeira gestão do Concidades Nacional. O projeto de lei que previa a organização do SNDU tinha como dispositivos gerais: (i) políticas de incentivo à implantação de instrumentos de promoção da função social da propriedade; (ii) instrumentos de participação e controle social no SNDU; (iii) a estruturação do Fundo Nacional de Desenvolvimento Urbano (FNDU); (iv) instrumentos e políticas de integração intersetorial e territorial.

O projeto de lei também previu os objetivos indicados na implementação do Sistema Nacional de Desenvolvimento Urbano, em que se destacam: (i) a redução do déficit habitacional; (ii) o acesso universal ao saneamento básico e gestão integrada da política; (iii) a ampliação da mobilidade urbana, priorizando o transporte coletivo e os não motorizados; (iv) a promoção da melhoria de qualidade de planejamento e gestão do território; (v) a democratização do acesso à informação; e (vi) a promoção da melhoria da qualidade ambiental urbana.

Apesar da estrutura política e organizativa do Estado frente às ações de planejamento urbano, questiona-se até que ponto tais marcos políticos e organizativos contribuíram de forma decisiva para a modificação dos processos de exclusão socioespacial, tornando as 
cidades brasileiras mais inclusivas, com melhor infraestrutura e acesso a bens produzidos coletivamente.

Desse modo, a análise sobre a organização da estrutura e ampliação de poder de controle para o governo tem se colocado na contramão da tendência neoliberal que difunde as ideias de minimização do papel do Estado. Ficam evidentes, ainda, os processos de expansão do capitalismo, na defesa cada vez mais ampliada da terra como mercadoria, "[...] a mais acabada materialização territorial e espacial das contradições do sistema produtor de mercadorias" (BURNETT, 2012, p. 101) que estão em oposição ao discurso e às normas que regem a política urbana após a Constituição de 1988.

Ribeiro e Cardoso (2003, p. 109) expõem que a política de investimentos urbanos no Brasil tem sido orientada pelos interesses do setor econômico, apontando que a agenda da contratação de obras públicas pelo Estado efetivamente tem atendido com maior prioridade aos interesses específicos das empreiteiras e de grandes projetos de desenvolvimento urbano, em prejuízo das necessidades da maioria da população.

Para Harvey (2005), o modelo de cidade pautado na lógica capitalista produz lucrativos e segregados espaços voltados ao consumo de apenas uma parcela da sociedade, a qual já é privilegiada. Esse modelo de cidade possui alicerce dentro da lógica do empresariamento das cidades (HARVEY, 1996). O empresariamento urbano caracterizar-seia, principalmente, pela parceria público-privada, tendo como objetivos políticos e econômicos imediatos muito mais o investimento e o crescimento econômico por meio de empreendimentos imobiliários pontuais e especulativos do que a melhoria das condições em um âmbito específico (HARVEY, 1996, p. 53); e pela mundialização financeira do capital, compreendida como um novo regime de acumulação predominantemente financeiro e globalizado que consiste em tornar as cidades mais atraentes para receber investimentos externos, sendo um importante instrumento para o desenvolvimento capitalista recente (CHESNAIS, 1993).

$\mathrm{Na}$ construção das cidades, a definição desses procedimentos materializa-se no cerne da burocracia e na gestão do território, permeada por redes de influência que articulam diversos setores empresariais, mandatos parlamentares e partidos políticos, já que empreiteiras de obras públicas, concessionárias de serviços, incorporadoras e construtoras são os maiores financiadores de campanhas eleitorais (ROLNIK, 2007, p. 38).

Ou seja, segundo Rolnik (2002), 
a estratégia de exclusão se dá também no nível da gestão e dos processos decisórios. O fato de as elites governarem historicamente para si mesmas, ao mesmo tempo abrindo espaços de extralegalidade negociada como resposta à pressão dos mais pobres, mostra que a democratização da gestão urbana não é só uma questão de bandeira política, mas a única possibilidade de invertermos essa situação. Abrir o processo de tomada de decisões sobre o investimento e controle do território urbano é um pressuposto para construirmos uma política urbana que inclua a totalidade dos atores sociais nas ações dos pactos federativos, visando à internacionalização e ao reconhecimento do direito à cidade como um direito humano emergente de caráter coletivo dos habitantes das cidades do século XXI (ROLNIK, 2002, p. 39).

Assim, o planejamento, a gestão das cidades e a política urbana compõem um arquétipo de diversas nuances que se consolidam no embate, enfrentamento e disputa de múltiplos projetos políticos no interior do Estado, nas relações de poder de atores e organizações e na materialidade do exercício da democracia no país que estão em permanente disputa.

\section{Considerações finais}

O presente artigo buscou trazer elementos gerais que perpassam pela organização política de desenvolvimento urbano brasileiro, evidenciando dois movimentos simultâneos e antagônicos que se expressam na análise conjuntural recente: a institucionalidade e criação de leis de desenvolvimento urbano que buscam assegurar direitos coletivos e que privilegiam a redistribuição de bens produzidos nas cidades com a participação social nos processos decisórios, e em contraponto um forte avanço do capital imobiliário com a prevalência de políticas elitistas, bem como a lógica do acesso à cidade e seus bens produzidos para o usufruto de poucos.

Observa-se na análise deste fragmento que o movimento em direção à construção de políticas urbanas de forma equânime não foi acompanhado pela formulação e revisão de um novo marco institucional e de organização do Estado no campo do desenvolvimento urbano nas instâncias públicas. 
Com isso, os desafios impressos no movimento da Reforma Urbana criam relevos entre o possível e o utópico, os encantos e os desencantos, que vão sendo traçados no campo de disputas na produção das cidades, num processo que ainda prevalece: a lógica de ações de planejamento e práticas pontuais, em detrimento de uma política urbana universalista, que garanta o acesso ao direito à cidade e um sistema ampliado de desenvolvimento urbano.

Sem dúvida, são relevantes conquistas que decorrem dos processos de organização coletiva e da proliferação de instrumentos legais na política urbana brasileira nas últimas décadas. No entanto, apesar dos avanços no discurso relativo ao direito à cidade, este não se traduz na definição de metas e estratégias efetivas para o enfrentamento da problemática urbana.

Como os autores Queiroz e Santos Junior (2011) definem:

O movimento da Reforma Urbana está desafiado a intervir programaticamente na cidade na forma de uma rebeldia criativa, buscando promover práticas educativas, políticas públicas e novas linguagens culturais geradoras da desmercantilização da cidade e da promoção do direito à cidade e rompendo, desta forma, com a hegemonia do neoliberalismo empreendedorista (QUEIROZ; SANTOS JUNIOR, 2011, p. 45).

A análise empreendida permite indicar que as políticas urbanas têm uma dimensão limitada, restritiva, ineficaz, se não assumirem um caráter igualitário universalizante e global. Não atuam no planejamento e em decisões mais amplas que possam ter um impacto significativo na estrutura da sociedade expresso no ideário da Reforma Urbana e do direito à cidade.

Por fim, o avanço da Reforma Urbana no Brasil carece, além da organização de uma nova reforma política alicerçada no fortalecimento de espaços de exercício da democracia direta e controle social (como preceitos já pautados na gestão democrática), impulsionar reformas estruturais, que aos poucos possam ser capazes de reverter a história de desigualdade e exclusão social na promoção efetiva de cidades mais justas e inclusivas. 


\section{Referências}

BRASIL. Constituição. Constituição da República Federativa do Brasil. Brasília: Senado, 1988.

Lei $\mathrm{n}^{\circ} 10.257$, de 10 de julho de 2001. Estabelece diretrizes gerais da política urbana. Estatuto da Cidade. Brasília: Câmara dos Deputados, 2001.

BURNET, C. F. G. Da tragédia urbana à farsa do urbanismo reformista: a fetichização dos planos diretores. 2009. 526 f. Tese (Doutorado em Políticas Públicas)- Universidade Federal do Maranhão, São Luís, 2009.

CHESNAIS, F. A mundialização do capital. São Paulo: Xama, 1996.

DAGNINO, E. Confluência perversa, deslocamento de sentidos, crise discursiva. In: GRIMSON, A. (Ed.). La cultura em las crises latino-americanas. Buenos Aires: Clasco, 2004.

DEÁK, C.; SCHIFFER, S. R. O processo de urbanização no Brasil. São Paulo: Editora da Universidade de São Paulo, 1999.

DYE, T. D. Understanding public policy. New Jersey: Prentice Hall, 1984.

FARIA, J. R. V. Planos Diretores participativos: a razão consensual no discurso da Reforma Urbana. 2012. 185 f. Tese (Doutorado em Planejamento Urbano e Regional)Instituto de Pesquisa e Planejamento Urbano e Regional, Universidade Federal do Rio de Janeiro, Rio de Janeiro, 2012.

FERREIRA, J. S. W. A cidade para poucos: breve história da propriedade urbana no Brasil. In: SIMPÓSIO INTERNACIONAL: Interfaces das representações urbanas em tempos de globalização, 2005, Bauru. Anais... Bauru: UNESP, 2005.

GOFFMAN, E. Os quadros da experiência social: uma perspectiva de análise. Petrópolis: Vozes, 2012.

GOHN, M. G. Conselhos gestores e participação sociopolítica. 3 ed. São Paulo: Cortez, 2007.

GUSSO, R. J. Pelas ruas e gabinetes: amplificando os frames da Reforma Urbana no Brasil. In: CONGRESO URUGUAYO DE CIENCIA POLÍTICA, 5., 2013, Montevideo. Ponencias..., Montevideo, 2013.

HARVEY, D. A condição pós-moderna. São Paulo: Loyola, 1993. 
. A liberdade da cidade. In: MARICATO. E. Cidades rebeldes: passe livre e as manifestações que tomam as ruas do Brasil. São Paulo: Boitempo, 2013.

Do gerenciamento ao empresariamento: a transformação da administração urbana no capitalismo tardio. Espaço e Debates, São Paulo, n. 39, p. 48-64, 1996.

HOBSBAWM, E. J. Os trabalhadores pobres. In.: HOBSBAWM, E. J. A era das revoluções. 4. ed. Rio de Janeiro: Paz e Terra, 1982.

IBGE. Instituto Brasileiro de Geografia e Estatística. Perfil dos municípios brasileiros 2009. Pesquisa de Informações Básicas Municipais. Rio de Janeiro: IBGE, 2010. Disponível em: $<$ www.ibge.gov.br/home/estatistica/.../perfilmunic/2009/munic2009.pdf $>$. Acesso em: 2 jan. 2015.

KOGA, D. Medidas de cidades: entre territórios de vida e territórios vividos. São Paulo: Cortez, 2003.

KOWARICK, L. A espoliação urbana. São Paulo: Paz e Terra, 1979.

LEFEBVRE, H. O direito à cidade. São Paulo: Moraes, 1991.

LOJKINE, J. O Estado capitalista e a questão urbana. São Paulo: Martins Fontes, 1997.

MARICATO, E.; SANTOS JÚNIOR, O. A. dos. As ideias fora do lugar e o lugar fora das ideias. In: ARANTES, O. et al. A cidade do pensamento único. Petrópolis: Vozes, 2000.

Construindo a política urbana: participação democrática e o direito à cidade. As metrópoles e a questão social brasileira. Rio de Janeiro: Revan, Fase, 2007.

QUEIROZ, L. C. R.; SANTOS JUNIOR. O. A. Desafios da questão urbana. Le Monde Diplomatique, ano 4, n. 45, abr. 2011.

RIBEIRO, C.; PONTUAL, V. A Reforma Urbana nos primeiros anos da década de 1960. Vitruvius, São Paulo, ano 10, n. 109.07, jun. 2009. Disponível em: $<$ http://www.vitruvius.com.br/revistas/read/arquitextos/10.109/50>. Acesso: 01 jan. 2016.

ROLNIK, R. É possível política urbana contra a exclusão? Serviço Social e Sociedade, São Paulo, Cortez, v. 72, p. 53-61, 2002.

Democracia no fio da navalha: limites e possibilidades para a implementação de uma agenda de Reforma Urbana no Brasil. Eure, Chile, v. 35, n. 104, p. 35-96, abr. 2009.

- Planejamento urbano nos anos 90: novas perspectivas para velhos temas. In: RIBEIRO, L.; JÚNIOR, O. (Orgs.). Globalização, fragmentação e Reforma Urbana: o futuro das cidades brasileiras na crise. Rio de Janeiro: Civilização Brasileira, 1994. 
SANTOS, M. A natureza do espaço. Técnica e tempo. Razão e emoção. São Paulo: Hucitec, 2002.

. A urbanização brasileira. São Paulo: Hucitec, 1993.

SANTOS JUNIOR, O. Democracia e governo local: dilemas da reforma municipal no Brasil. Rio de Janeiro: Revan, Fase, 2001.

Políticas públicas, arenas e atores sociais: o Fórum Nacional de Reforma Urbana e a agenda pelo direito à cidade. ENCONTRO DA ASSOCIAÇÃO NACIONAL DE PÓSGRADUAÇÃO E PESQUISA EM PLANEJAMENTO URBANO E REGIONAL, 13., 2009, Florianópolis. Anais... Florianópolis, 2009.

VILLAÇA, F. Uma contribuição para a história do planejamento urbano no Brasil. In: DEÁK, C.; SCHIFFER, S. R. (Orgs.). O processo de urbanização no Brasil. São Paulo: EDUSP, 1999.

Artigo recebido em 04/01/2016. Aceito para publicação em 26/01/2016. 